\title{
Building Social Capital through Leadership Development
}

\author{
Cynthia Roberts \\ Purdue North Central \\ Westville, IN 46391 \\ 219-785-5219 \\ croberts@pnc.edu
}

\begin{abstract}
Social capital, an important mechanism for the creation and maintenance of healthy organizational life, may be developed through initiatives such as leadership development as effective leadership development not only enhances individual effectiveness, but serves to build relationships, coordinate actions, and extend and strengthen the social network. An ongoing iterative process which engages all participants such as action learning can facilitate this process. This research supports the connection between leadership development and social capital based on an extended action learning engagement in a healthcare system.
\end{abstract}

\section{Introduction}

Social capital, once studied primarily in the social and political sciences, has become increasingly important in the organizational sciences as a mechanism for the creation and maintenance of healthy organizational life (Adler \& Kwon, 2002; Timberlake, 2005; Cohen \& Prusak, 2001). Putnam (2001) defined social capital as "the connections among individuals - social networks and the norms of reciprocity and trustworthiness that arise from them" (p.19). Cohen and Prusak (2001) further elaborated in their definition when they wrote that "the stock of active connections among people: the trust, mutual understanding, and shared values and behaviors that bind the members of human networks and communities and make cooperative action possible" (p. 4).

High levels of social capital have been shown to have a positive impact on multiple facets of organizational life including individual career success, compensation and placement, employee recruitment and retention, team effectiveness, interdepartmental resource exchange, product innovation and entrepreneurship, as well as external relationships with suppliers, regional production networks and other firms (Adler \& Kwon, 2002; Oh, Labianca, \& Myung-Ho, 2006). Higher levels of trust, common frames of reference, shared goals, and the cooperative spirit associated with high levels of social capital can result in better knowledge sharing, lower transaction costs, lower turnover costs, greater coherence of action (Cohen \& Prusak, 2001), and greater intellectual capital (Nahapiet \& Ghoshal, 1998). Individuals not only have greater access to 
information, but also greater power, influence, and control to get things done when they leverage their social capital across boundaries between organizational units. In addition, strong networks build solidarity and facilitate resolution of disputes and grievances (Adler \& Kwon, 2002). However, although there are numerous positive effects, negative manifestations of social capital can result in ethnocentrism, sectarianism, corruption and the inhibition of innovation or risk taking (Putnam, 2001; Adler \& Kwon, 2002).

Putnam (2001) suggested that there are two types of social capital; bonding, which facilitates strong inwardly focused fairly homogenous groups, and bridging, which extends outward to include many diverse constituencies. Both serve useful purposes. Bonding social capital provides social and psychological support for its members creates solidarity and facilitates reciprocity. Bridging social capital can facilitate information dissemination and linkage to external resources. The notion of social capital has also been associated with more contemporary forms of leadership (King, 2004) as the definition of leadership has expanded from a set of traits residing in one individual, to a function of the collective (Barker, 2001; Dachler \& Hosking, 1995; Marion \& Uhl-Bien, 2001; Rost, 1991; Raelin, 2003).

Although the benefits of social capital have been documented, it is nonetheless difficult to build (Timberlake, 2005; Adler \& Kwon, 2002; Prusak \& Cohen, 2001). Organizational leaders can however, expand social capital by building trust through transparency and authentic leadership, providing time and space to create connections and facilitate personal conversations, and establishing recognition and reward systems that support and reinforce collaboration (Nahapiet \& Ghoshal, 1998; Prusak \& Cohen, 2001). Leadership development may serve as one effective strategy for building social capital by not only enhancing effectiveness of the individual leader, but also by serving to build relationships, coordinate actions, and extend and strengthen the social network (Day, 2001; Day \& Harrison, 2007). Van de Valk's (2008) review adds further clarity to the relationship between leadership development and the social network and encourages additional study. This research supports the connection between leadership development and social networking through an action learning process in one healthcare system.

\section{Leadership Development through Action Learning}

Organizations intending to build effective leadership capacity need to develop both individual human capital as well as collective social capital. Development of both individual leaders and collective leadership is needed (Day, 2001; Day \& Harrison, 2007; Van Velsor \& McCauley, 2004). Leader development according to Van Velsor and McCauley (2004) is defined as “the expansion of a person's capacity to be effective in leadership roles and processes...those that facilitate setting direction, creating alignment, maintaining commitment in groups of people who share common work" (p. 2). Individuals must become cognizant of 
their own values, develop greater self-awareness and an ability to continuously learn, think, and act creatively and strategically (Day, 2001; Van Velsor \& McCauley, 2004).

According to Van Velsor and McCauley (2004), leadership development addresses the collective and encompasses "the expansion of the organization's capacity to enact the basic leadership tasks needed for collective work" (p. 18). Leadership is developed through building interpersonal skills, social awareness, mutual respect, and trust. If organizational leaders can shift their viewpoint of leadership from a characteristic residing in an individual to a phenomenon that is a property of the whole system, and if they can create opportunities for connection, then leadership capacity and therefore social capital will be enhanced (O'Connor \& Quinn, 2004).

Due to its collaborative nature action learning is well suited to facilitate leadership development (Coghlan, 2004; Day, 2001; Raelin \& Coghlan, 2006; Torbert, 1994). If one intends to develop collective capacity, then a collective process must be utilized to do so (Raelin, 2006; James, Mann, \& Creasy, 2007). Action learning, originally introduced by Revans (1980), is a model of experiential learning in which participants learn by incorporating programmed knowledge with questioning insight. Central to the process is its cyclical nature, an engagement with real issues, a process of inquiry that attempts to uncover all aspects of a particular issue in question, exploration of potential resolutions through action and reflection, and promotion of a group dynamic that encourages critical reflection and learning (Revans, 1998). According to Revans (1980), "action learning is about real people tackling real problems in real time, observing the impartial discipline of the business setting and looking after a lot of people" (p. 309). The use of external experts is minimal, and participants take control of their own learning (Zuber-Skerrit, 2002). Conversations between members serve as the cornerstone of this process to construct new meaning and transform collective experiences into personal, group, and organizational knowledge (Baker, Jensen, \& Kolb, 2005; King, 2003; Raelin, 2001).

The outcomes of action learning programs can include improved strategic thinking ability, understanding group processes and organizational change, improved understanding between sections of the organization, development of leadership skills, and more ideas for future projects (Zuber-Skerrit, 2002). In addition, as participants work on their own issues, they develop stronger relationships, are more in control of the information, and are empowered to act in the future. This process can increase each member's capacity to collaborate as the individual develops a sense of self-efficacy, meaning, and responsibility. At the group level mutual inquiry can promote critical thinking, team learning, and enhanced interpersonal interactions (Raelin \& Coghlan, 2006). The social networks that develop based on the collective experiences, shared values, and mutual trust creates an organizational infrastructure that supports information 
dissemination well beyond the completion of the consulting engagement (Bradbury \& Reason, 2003; Day, 2001).

\section{The LEAD Program}

The Leadership Education and Development (LEAD) program was established six years ago at a regional health system (Health Systems). The program, explicitly intended to develop leadership at all levels for increased personal and organizational effectiveness, was offered initially to all members of the management team and subsequently expanded to include coordinators, team leaders, and other interested employees. The content incorporated into the programming, as well as its delivery, was the result of a collaborative effort between the university and the members of hospital administration from the Human Resource and Organizational Development departments.

Program participants came from all disciplines within Health Systems and represented a variety of departments; patient care, diagnostics, administrative support, ancillary services, and off-site satellite facilities. The tenets of action learning served as the springboard for the leadership development process in this project. Each cycle of the LEAD program consisted of a series of meetings, each lasting three hours, convened every other month over a six month period. Each workshop not only provided the theoretical background and a platform for skill development at the individual level, but also an opportunity for members to share learning, give and receive feedback, and to develop action plans for the future. Two levels of programming were offered and included topics such as personality, servant leadership, communication and conflict management, coaching and performance management, delegation, change management, and appreciative inquiry. Participants in the program were organized into small groups, and encouraged to discuss how this could be applied in their setting. In addition, upon completion of each session participants were encouraged to put into practice a relevant concept and then share their experience when they reconvened at the next session. Each subsequent session began with a review of the concepts from the prior session, a dialogue around how the concepts were put into use, and the successes or challenges that arose. Care was taken to ensure that topics addressed were consistent with the organization's mission and values.

Key issues that emerged during conversations were also shared with members of the hospital executive team when appropriate. Subsequent programming and topics for further discussion were later refined based on participant feedback. Over time the sessions became more collaborative and, according to the participants, as they became more familiar and comfortable with each other the peer-to-peer conversations and sharing emerged as one of strong features of the program. A total of 110 individuals grouped into three cohorts participated in at least one level of the LEAD program. Two of the three cohorts completed both levels of the LEAD program. The third cohort only completed the first phase prior to program suspension due to economic reasons. 


\section{Methods and Data Collection}

This study engaged action research as the primary means for gathering data, making sense of that data, and revising programming as needed. Action research, due to its participative nature as well as adoption of an inside-out perspective, is well suited to study leadership development as it unfolds, as a contextuallydriven, reflective, and relational process (Coghlan, 2004; Torbert, 1994, 2004). Since we have primarily employed an action learning approach in the leadership development program, it is only fitting that a similar action-oriented approach be used as the primary research method.

According to Coghlan and Brannick (2005), action research cycles through various stages from diagnosis to action planning to taking action and evaluating the results. The process is iterative as well as reflective. Process, results and, key elements of learning are continually refined by the group as data is generated over time. Action research is also collaborative in that both the researcher and group decide upon issues to study, create strategies for action and reflect upon results. In addition, the outcome of action research not only benefits the client, but enhances the development of the researcher and contributes to a broader knowledge base (Reason \& Torbert, 2001).

Working collaboratively with members of the administrative team, several opportunities for cyclical planning, data collection, action, and reflection were developed. Each process is briefly described below. Although leadership development research may involve conventional quantitative analyses, this study employed the use of narrative and dialogic approaches because the participants were as involved in the process as the researchers (Raelin \& Coghlan, 2006; Raelin, 2006; Bradbury \& Reason, 2001; Wenger, 2000). The use of multiple cycles and venues serves to provide credibility to the findings.

\section{Process 1: Workshop Sessions}

Each workshop, designed to use an action learning approach (Raelin, 2006), provided an opportunity for members to learn new concepts, share issues, collaborate to solve problems, become more familiar with larger organizational issues, and become better acquainted with each other. Upon conclusion of each session, participants were requested to complete and submit a short feedback form. During the last session of each level of programming participants were additionally requested to reflect upon the series, discuss key element of what they learned, offer ideas for subsequent sessions, and begin to engage in action planning. Although ideas were discussed collectively, members of all groups were again requested to complete a feedback form to ensure all voices were heard. Both sets of forms were analysed for key themes and the data generated was shared with members of the administration to refine format and content going forward. 


\section{Process 2: Lunchtime Inquiry Group}

A group of approximately 12 managers who were actively involved in the program met monthly during lunchtime over a five-month period. Sessions were loosely based on the cooperative inquiry approach outlined by Heron and Reason (2001), recorded, transcribed and analysed using the methodology suggested by Strauss and Corbin (1998). The intention was to create a more intimate setting whereby the group could further delve into the collaborative learning process, explore issues around leadership, garner feedback about the formal LEAD programming, gain insight into larger organizational issues, and perhaps develop strategies for change. After each session a report was created and shared with the group at the next session for validation. The reports also served as a way to maintain focus and follow up on key issues. Moreover, they triggered further dialogue, reflection, sharing, and learning.

\section{Process 3: Periodic Meetings with Administrative Personnel}

A series of meetings with members of the administrative team were conducted in order to share and clarify findings, establish mutual goals, determine additional areas of study, and discuss any other program matters. This group served as the action research team and sounding board for the entire program.

\section{Process 4: One-on-one Dialogues with Participants}

In addition to the inquiry group, conversations were held with 11 additional program participants to gather their insights, impressions, key elements learned, and suggestions. All dialogues were recorded, transcribed, and analysed for key themes. The group included representation from clinical, support, and satellite facilities of Health Systems.

\section{Process 5: Personal Observations and Reflections}

Immediately after each encounter or session, impressions, thoughts, and personal reflections of the author were captured via recording. Recordings of each personal entry were transcribed and analysed for key themes and what was learned as well as unanswered questions going forward in the process.

\section{Results and Program Outcomes}

Although much has been written about leadership development, Collins (2001) noted that little work has been done to assess the effectiveness or outcomes of leadership development initiatives. Because leadership development encompasses multiple levels from the individual to collective, it only follows that assessment of the outcomes should occur using various levels as well (Day, 2001; Leatt \& 
Porter, 2003; Yammarino, Dansereau, \& Kennedy, 2001). Therefore, this section addresses development that occurred at individual as well as collective levels such as the group and organization. Intragroup relationships suggesting bonding social capital as well as interdepartmental bridging social capital are illustrated as well as changes effected within the organization. The key outcomes are summarized in Table 1 and representative comments have been italicized. 
Table 1

Outcomes of the LEAD program

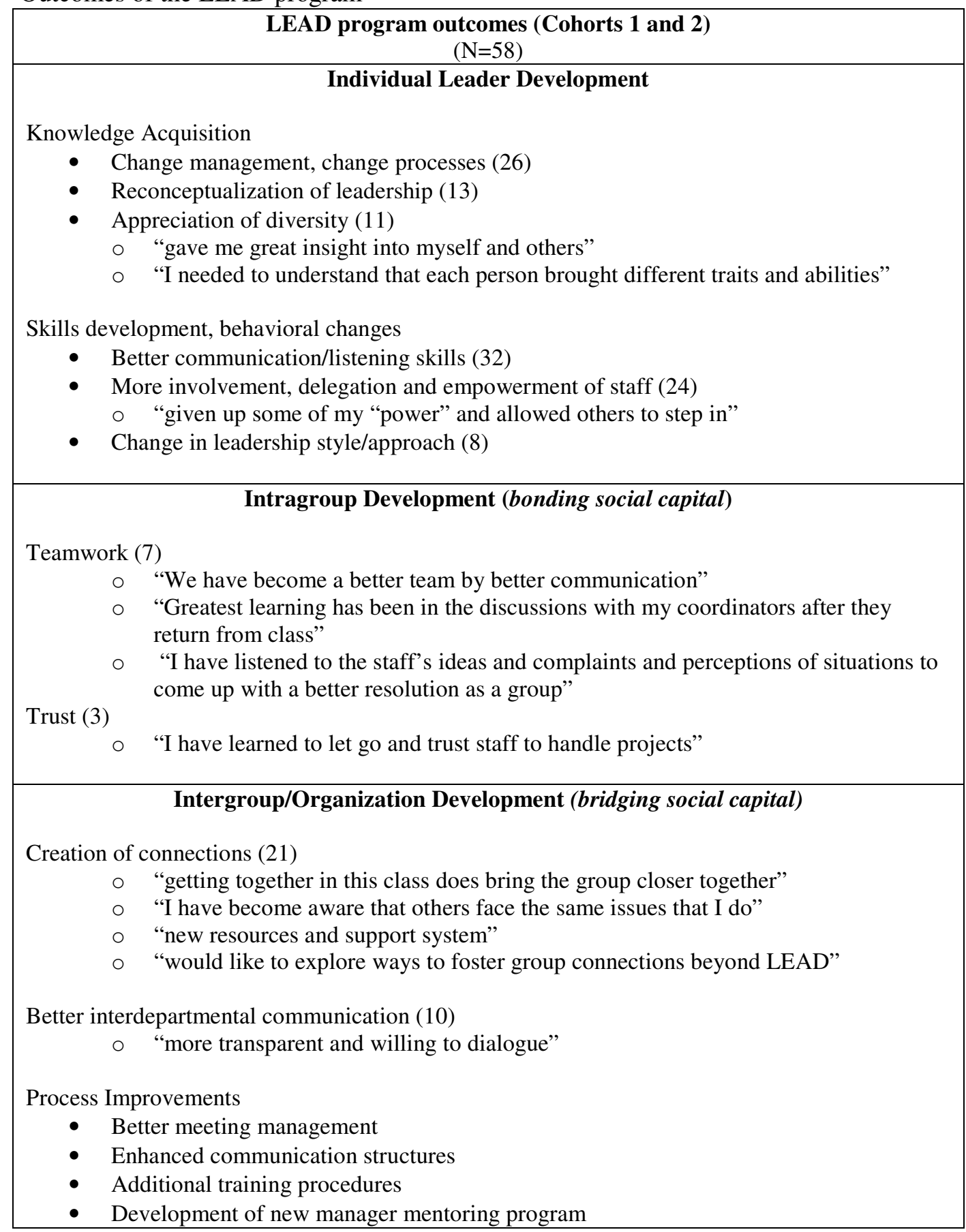




\section{Individual Leader Knowledge Acquisition and Relational Skills Development}

Since an action learning approach was utilized, individuals were able to learn what was relevant to them, reflect upon that learning, and use that information back within their own setting. The data suggested that both cohorts experienced several of the same learning points which included a reconceptualization of the notion of leadership, better understanding and appreciation of style and generational differences, and a more complete understanding of the process of change management. In addition, junior team leaders with less experience from the second cohort reported that they had developed more self-confidence and comfort within their roles as leaders.

The LEAD Program participants also reported that they had developed additional relational skills. Participants from both cohorts noted better communication skills, increased involvement and empowerment of their staff, more delegation, and a shift to employing more developmental forms of performance management such as coaching and mentoring. In addition to self-reports of learning and behavior change, the junior team leaders in the second cohort had the opportunity to share their observations of changes that they had noticed in their own managers who had gone through the program previously. Their reports also corroborated the self reports of more communication, involvement and delegation - "I can definitely tell a difference in how he talks with staff, and listens to them more, and just his responses back and how they're worded has made a big difference. (J)"

\section{Group Intradepartmental Dynamics, Processes and Bonding Social Capital}

A theme which frequently emerged throughout the meetings related to a concern with relationships within individual departments or units. Teambuilding, dealing with dysfunctional group dynamics, employee performance, coaching, and delegation were all discussed. One manager implemented a department-wide career ladder and noted that this had helped retain entry-level employees. Another reported that she had changed the physical layout of her unit to promote more dialogue and collaboration between caregivers and support personnel. Several participants reported that they have seen better teamwork within their department. Others noted more collaborative problem solving and a willingness to share leadership.

Tenure within a leadership role also affected the focus of the participants. The first cohort consisted of fairly experienced managers and directors. As the program was offered to others in the organization, subsequent cohorts consisted of less experienced team leaders. Those who had been in a management position for some time appeared to focus more on global organizational issues while those who were relatively new had concerns that were much more locally focused. For 
example, the participants in the less senior, second cohort were much more interested in how the programming would help in the immediate context of their team, and conversations centered on personal struggles in making the transition to a leadership role, internal operational issues such as staffing and training, relationship building through better communication, addressing generational issues, improving morale, and facilitating more involvement of their team members. One group of team leaders actually left a session only to return later with a new staffing plan for the third shift. Another team leader worked with her group to develop a strategy for training nurses how to operate a new piece of diagnostic equipment.

The first cohort, consisting of more senior managers, discussed some of the same challenges; however, this group went further to grapple with issues dealing with organizational policies and procedures. Topics explored included the logistics and challenges associated with implementation of a new 360 evaluation process, exploration of a new process for conducting meetings across the organization, development of a process for a scheduling meetings, perception of changes in organizational culture, and consideration of a system-wide mentoring program for new managers. This group also expressed some frustration with the organization and was quick to call attention to those administrators who did not model behavior consistent with concepts presented in the LEAD program.

\section{Organization Development of Leadership and Bridging Social Capital}

The LEAD program facilitated the growth of the individual leader as it supported the development of connections necessary for the practice of collective leadership, both of which are necessary for effectiveness (Day, 2001; Day \& Harrison, 2007; Raelin, 2003; James, Mann, \& Creasy, 2007). Bartol and Zhang (2007) suggested thinking of leadership development outcomes in terms of the creation of multiple linkages or networks which can foster more effective processes in three very important ways: task accomplishment and problem solving (task), career advancement and mentoring (career), and friendship and emotional support (support). In this case, the creation of connections was seen as one of the major outcomes of the LEAD program as the appreciation for having the opportunity for dialogue and collaboration repeatedly emerged. The importance of connectivity, bridging professional practice silos, particularly in a historically fragmented organization such as a hospital, cannot be underestimated:

\section{- Task accomplishment and problem solving}

"and I really like getting together with the other leaders in the organization and just hearing how they deal with things and learning some other techniques and dealing with things. The most helpful part to me in working through, like, a situation, you know, how you handle this. But I like that kind of group thing" (JE). 


\section{- Career advancement and mentoring}

"I think it's very, very helpful to be able to hear from your peers with any organization, the same struggles that they are going through, how they approach things, how you deal with it, and it has also been very helpful too because then the people have dealt with it they know about, well there was this policy or this. It's kind of little tidbits of information to help you along the way or to give you ideas and also to practice" (JU).

"One of the cool things about LEAD is getting to know others who we might not otherwise have known. I am going to point at R. Before LEAD, I didn't spend much time with R. I didn't know her and I've gotten to know her. That is a real positive because she has a wealth of knowledge and information and I can use her comfortably as a resource in my work life. I never would have had that so you know the positive things from the group and from the LEAD courses is that I am learning more and more about these people that I see every day. You don't know or appreciate that much. So it's given me an opportunity there" (L).

\section{- Friendship and emotional support}

"I think that we are starting to understand what's going on in everybody's department and you are starting to get that bond the more we meet - again the power of that group. You know the other managers and now you feel that you can support them if they wanted it" (V).

"I like it because when you have a chance to listen to other people in the hospital that are having the same issues that you are having, it's almost like a relief. You're having these struggles with whether it be employees or whether it be problems within your department, not necessarily people, but computers or whatever, and you have people who have those same issues. You can say, okay, it's not just me" (R).

"I think what it is, is we don't understand each other until we get to know each other. I have no clue what the x-ray guy does all day. I don't have a clue what the ER guys do, and they don't have a clue what I'm doing. I think once we start talking to each other and we meet each other, that we gain that respect from each other" (T).

The members of the first, more senior cohort, appeared to be a much more connected group from the very beginning based on the ease and frequency of interaction. This was not surprising as they routinely worked together on various task forces within the hospital. Members routinely consulted with each other when working through problems as well as for emotional support. The members of this cohort have also disclosed that they were ready to develop their network 
even further and were willing to take action on certain organizational projects such as taking responsibility for the weekly meeting forums, developing a new manager mentoring program, working through holiday coverage issues, building trust between each other, and working more closely with upper administration. Some incidents of collective sense-making occurred as participants discussed changes in organizational structure and key personnel, the dialectic of empowerment within the context of a formal hierarchal structure, and organizational strategies for leveraging their time more effectively (i.e., meetings, emails, schedules). As several of the managers noted, they had begun to work from a systems-thinking perspective by involving others from outside of the unit when appropriate.

Initially the members of the second cohort, consisting of less experienced team leaders and coordinators, did not appear to be as connected to each other as the first group. Since the majority of their focus up until the point of the program was directed internally, this was to be expected as members most likely did not have much opportunity to interact or collaborate outside of their own department. Over time, however, members became more acquainted, developed trust in each other, and began to work through multiple problems together.

\section{Discussion}

The process of leadership development has emerged in this organization in a manner that includes the growth of individual leaders as well as the development of collective leadership capacity and social capital. Multiple cycles of action learning and inquiry can facilitate this process. This paper provides a unique contribution to the leadership development literature by integrating not only the individual leader but the development of social capital, ultimately increasing the capacity to stimulate organizational change.

\section{Leader Development}

In order for effective leadership to emerge, one must begin with the development of the individual first. This phase is addressed in most traditional leader development programs and focuses on building individual knowledge and skills (Day, 2001). Implicit notions of leadership and an internal focus are gradually replaced by more collective concepts (Lord \& Hall, 2005; Rooke \& Torbert, 2005). In the earliest sessions of the LEAD program, one discovers new ways of thinking about leadership, develops appreciation for differences, and assimilates more effective relational and managerial skills. Initially less experienced participants may struggle with thinking of themselves as a leader; however, over time the concept of leader becomes a part of one's identity. This can enhance one's sense of self-efficacy, empowerment, and intrinsic motivation to stretch beyond one's comfort level to try new behaviors (Lord \& Hall, 2005; Raelin, 2006). Development of a more collaborative style allows for the individual to engage others in problem solving, learning, and information sharing which sets 
the stage for increasing connections and network development, all of which are hallmarks of contemporary notions of leadership.

\section{Development of Leadership and Social Capital}

The collaborative nature of action learning provides relevance, encourages reflection, and helps to develop interdisciplinary relationships or networks that continue even after the programming is finished (Raelin, 2006; Raelin \& Coghlan, 2006; Torbert, 1994). The expansion of interdisciplinary networks can result in increased social capital which is essential to individual, group, and organizational effectiveness (Adler \& Kwon, 2002; Bartol \& Zhang, 2007; Nahapiet \& Ghoshal, 1998; King, 2004; O'Connor \& Quinn, 2004). The development of social capital involves not only the creation of new connections and the enhancement of relational dynamics such as respect, trust, shared norms, values, and expectations, but also allows for a cognitive recognition of a collective identity through shared language and meaning making (Nahapiet \& Ghoshal, 1998).

One of the distinctive aspects of the LEAD program that evolved over time was the focus on building relationships and collaborative learning. Participants reported not only developing better relationships within their department (i.e., bonding social capital) but they also emphasized the importance of the new relationships built across departmental and functional lines (i.e., bridging social capital). In this context, the value of the collaborative process may be fourfold:

- Assistance in the transition to leader through the establishment of a new peer group which transcends practice boundaries or organizational silos As a manager incorporates the notion of leader into her identity, she finds it necessary to shift her affiliation with a particular peer group from one that is discipline specific (e.g., nurse, technician) to one that is interdisciplinary and position specific (manager, director). As (S) noted, "we talk about departments being in silos, but it is really easy for us to become one person silos." And (P) elaborated "so the only group that I have to talk to sometimes IS this group. You know, I can't address my employees the same way that I would address some of my friends. Why I think this group is so important is because I think that we are pretty much colleagues and peers."

- Provision of psychological safety - Edmundson (1999) noted the importance of psychological safety to team learning. The supportive environment provided by the LEAD program may provide a degree of psychological safety for some members to take risks and share their dilemmas, ultimately enhancing the learning of all. In addition, they can serve as sounding boards to work through issues that might otherwise be too sensitive to discuss in other arenas (Raelin, 2006). As (R) noted in one of our meetings: "nobody wants to call another director and say 'you know, I am really not good at this what should I do?' In a group setting, 
you are getting a lot of tools and a lot of ideas on how to solve difficult issues"

- Development of a stronger network through creation of communities of practice or learning communities which can assist in problem solving, professional skill development, and the transfer of best practices (Senge, 2004; Wenger, 2000) - Communities of practice can help build social capital by serving as an internal clearing house for identifying those individual who have knowledge related to a particular issue, allowing for increased access to information as well as alternative perspectives, and connect newer members to resources necessary for them to be successful (Akdere \& Roberts, 2008; O'Connor \& Quinn, 2004). Several members noted that they have learned a great deal from their colleagues and have recognized that they have more in common than originally perceived, grappling with many of the same issues such as problematic employees, budgetary constraints, or organizational policies. This recognition has helped members feel more connected, supported and willing to share information. In addition, members have reported a greater appreciation and understanding of issues not affecting their immediate areas. A community of practice which joins together participants from different professional disciplines may also help alleviate some of the isolation and fragmentation issues found in healthcare organizations as noted by Ranga and Rousseau (2006).

- Creation of relational space - Bradbury and Reason (2001) asserted that the creation of relational space precedes the development of collaborative work between different organizational entities. This appears to be important even within the context of one organization such as Health Systems due to the fragmented nature of healthcare institutions in general. As members develop trust, peer-to-peer learning becomes possible. Over time the connections can result in collaborative efforts and action across the organization.

\section{Organizational Impact}

Effective leadership development processes should also enhance organizational capability for meeting complex challenges that are larger than any one set of individuals (Raelin, 2003). O'Connor and Quinn (2004) maintained that expanded leadership capacity which allows for multiple responses to any given situation is essential to organizational health and survival. This increased capacity becomes evident through organizational changes and improvements in performance such efficiency and productivity gains, process improvements, innovation and adaptation, or improved employee relations (Yukl \& Lepsinger, 2005). These changes became evident at Health Systems as well. Several new initiatives emerged from the conversations held within the sessions including a new meeting management procedure, the revision of an organizational communication 
processes, and the development of additional training for a new performance management system. Participants also reported that they would like to continue their network development beyond the scope of the program, offer programming to everyone within the system, and continue to collaborate to resolve organizational issues going forward.

\section{Limitations and Need for Further Study}

Although members of both cohorts reported that they had begun using more collaborative approaches; therefore, future studies should involve the use of social network analysis (Raelin, 2006; Mayo, Meindl, \& Pastor, 2002). Elements of social networks that may assist in ascertaining network growth include network density or the number of ties within an organization, strength or frequency of ties, symmetry or directionality of exchanges, and degree of centrality or the number of ties that can be attributed to each member. In addition, social capital can be further assessed by determining the levels of trust within an organization as well as the exploration of norms and shared narratives (Nahapiet \& Ghoshal, 1998).

\section{Conclusion}

Social capital, an important mechanism for the creation and maintenance of healthy organizational life, may be developed through initiatives such as leadership development as it works to develop the individual leader and foster collective leadership. An ongoing iterative process such as action learning which engages all participants can facilitate the development of bonding social capital between members within a group as well as bridging social capital by strengthening the relationship between groups, departments, or disciplines. Working across disciplines will help to facilitate greater organizational learning, creativity, and process gain. 


\section{References}

Adler, P. S., \& Kwon, S.-W. (2002). Social capital: Prospects for a new concept. Academy of Management Review, 27(1), 17-40.

Akdere, M., \& Roberts, P. B. (2008). Economics of social capital: Implications for organizational performance. Advances in Developing Human Resources, 10(6), 802-816.

Baker, A. C., Jensen, P. J., \& Kolb, D. A. (2005). Conversation as experiential learning. Management Learning, 36(4), 411-427.

Barker, R. (2001). The nature of leadership. Human Relations, 54(4), 469-494.

Bartol, K. M., \& Zhang, X. (2007). Networks and leadership development: Building linkages for capacity acquisition and capital accrual. Human Resource Management Review, 17(4), 388-401.

Bradbury, H., \& Reason, P. (2001). Broadening the bandwidth of validity: Issues and choice-points for improving the quality of action research. In P. Reason \& H. Bradbury (Eds.), Handbook of Action Research (pp. 447455). London: Sage.

Bradbury, H., \& Reason, P. (2003). Action research: An opportunity for revitalizing research purpose and practices. Qualitative Social Work, 2(2), 155-175.

Coghlan, D. (2004). Action research in the academy: Why and whither? Reflections on the changing nature of research. Irish Journal of Management, 25(2), 1-10.

Coghlan, D., \& Brannick, T. (2005). Doing action research in your own organization ( $2^{\text {nd }}$ ed.). London: Sage Publishing.

Cohen, D., \& Prusak, L. (2001). In good company: How social capital makes organizations work. Boston: Harvard Business School Press.

Dachler, H. P., \& Hosking, D. M. (1995). The primacy of relations in socially constructing organizational realities. In D. M. Hosking, H. P. Dachler \& K. J. Gergen (Eds.), Management and Organization: Relational Perspectives (pp. 1-29). Brookfield, VT: Avebury/Ashgate Publishing.

Day, D. V. (2001). Leadership development: A review in context. The Leadership Quarterly, 11(4), 581-613. 
Day, D. V., \& Harrison, M. M. (2007). A multilevel, identity-based approach to leadership development. Human Resource Management Review, 17(4), 360-373.

Drath, W. (2001). The deep blue sea: Rethinking the source of leadership. San Francisco: Jossey-Bass Publishers and Center for Creative Leadership.

Heron, J., \& Reason, P. (2001). The practice of co-operative inquiry: Research "with" rather than "on" people In P. Reason \& H. Bradbury (Eds.), Handbook of Action Research (pp. 179-188). London: Sage Publications.

James, K.T., Mann, J., \& Creasy, J. (2007). Leaders as lead learners: A case example of facilitating collaborative leadership learning for school leaders. Management Learning 38(1), 79-94.

King, I. W. (2003). Making space: Valuing our talk in organizations. Journal of Management Studies, 40(5), 1205-1223.

King, N. K. (2004). Social capital and nonprofit leaders. Non-Profit Management and Leadership, 14(4), 471-486.

Leatt, P., \& Porter, J. (2003). Where are the healthcare leaders? The need for investment in leadership development. Healthcare Papers, 4(1), 14-31.

Lord, R. G., \& Hall, R. J. (2005). Identity, deep structure and the development of leadership skill. The Leadership Quarterly, 16(4), 591-615.

Marion, R., \& Uhl-Bien, M. (2001). Leadership in complex organizations. The Leadership Quarterly, 12(4), 389-418.

Mayo, M., Meindl, J., \& Pastor, J. (Eds.). (2002). Shared leadership in work teams: A social network approach. Thousand Oaks, CA: Sage.

Nahapiet, J., \& Ghoshal, S. (1998). Social capital, intellectual capital, and the organizational advantage. Academy of Management Review, 23(2), 242266.

O’Connor, P., \& Quinn, L. (2004). Organizational capacity for leadership. In E. Van Velsor, \& McCauley, C. (Eds.), The Center for Creative Leadership Handbook of Leadership Development (pp. 417-437). San Francisco: Jossey-Bass.

Oh, H., Labianca, G., \& Myung-Ho, C. (2006). A multilevel model of group social capital. Academy of Management Review, 31(3), 569-582. 
Prusak, L., \& Cohen, D. (2001). How to invest in social capital. Harvard Business Review, 79(6), 86-93.

Putnam, R. (2001). Bowling alone: The collapse and revival of American community. New York: Simon and Schuster.

Raelin, J. (2003). Creating leaderful organizations: How to bring out leadership in everyone. San Francisco: Berrett-Kohler Publishers.

Raelin, J. A. (2001). Public reflection as the basis of learning. Management Learning, 32(1), 11-30.

Raelin, J. (2006). Does action learning promote collaborative leadership? Academy of Management Learning \& Education, 5(2), 152-168.

Raelin, J. A., \& Coghlan, D. (2006). Developing managers as learners and researchers: Using action learning and action research. Journal of Management Education, 30(5), 670-689.

Ranga, R., \& Rousseau, D. (2006). The challenges are organizational not just clinical. Journal of Organizational Behavior, 27(7), 811-827.

Reason, P., \& Torbert, W. R. (2001). The action turn: Toward a transformational social science. Concepts and Transformation, 6(1), 37.

Revans, R. (1980). Action learning: New techniques for managers. London: Blond and Briggs.

Revans, R. (1998). ABC of action learning: Empowering managers to act to learn from action. London: Lemos and Crane.

Rooke, D., \& Torbert, W. R. (2005). Seven transformations of leadership. Harvard Business Review, 83(4), 66-76.

Rost, J. (1991). Leadership for the twenty-first century. Westport, CT: Greenwood Publishing.

Senge, P. (2004). Creating communities. Executive Excellence, 21(9), 4-5.

Strauss, A. \& Corbin, J. (1998) Basics of qualitative research. London: Sage.

Timberlake, S. (2005). Social capital and gender in the workplace. Journal of Management Development, 24(1), 11.

Torbert, W. R. (1994). Managerial learning, organizational learning: A potentially powerful redundancy. Management Learning, 25(1), 57-70. 
Van De Valk, L. J. (2008). Leadership development and social capital: Is there a relationship? Journal of Leadership Education, 7(1), 47-64.

Van Velsor, E., \& McCauley, C. (2004). Our view of leadership development. In Van Velsor, E. \& C. McCauley. (Eds.), The Center for Creative Leadership Handbook of Leadership Development (pp. 1-22). San Francisco: Jossey-Bass.

Wenger, E. S., W. (2000). Communities of practice: The organizational frontier. Harvard Business Review (Jan-Feb), 16.

Yammarino, F. J., Dansereau, F., \& Kennedy, C. J. (2001). A multiple-level multidimensional approach to leadership: Viewing leadership through an elephant's eye. Organizational Dynamics, 29(3), 149-164.

Yukl, G., \& Lepsinger, R. (2005). Why integrating the leading and managing roles is essential for organizational effectiveness. Organizational Dynamics, 34(4), 361-375

Zuber-Skerrit, O. (2002). The concept of action learning. The Learning Organization, 9(3), 114-124. 


\section{Author Biography}

Cynthia Roberts is a Professor of Organizational Behavior and Leadership, Director of the MBA Program, and Interim Dean of the College of Business at Purdue University North Central. Her teaching and research interests include leadership and leadership development, organizational behavior, group dynamics, and gender issues in leadership. She earned a doctorate in Organization Development from Benedictine University and M.S. degrees in Training and Organization Development from Loyola University Chicago. Roberts is also a Registered Organizational Development Professional (RODP) and has worked to facilitate leadership development with numerous clients in healthcare, retail, banking, and manufacturing. 